\title{
DRIVERS OF EMPLOYMENT OUTCOMES AMONGST SKILLED MIGRANTS TO AUSTRALIA
}

\author{
Justin van de Ven and Sarah Voitchovsky
}

The University of Melbourne

\begin{abstract}
During the last 2 decades Australia has very substantially increased its skilled migration intake to offset the effects of declining fertility and increased longevity. Between 1996 and 2011, permanent arrivals in Australia rose from 85000 to 195000 per year, with 83 per cent of the increase accounted for by migration through the Skill Stream. Furthermore, since the mid-2000s Australian skilled migration policy has shifted from a "supply driven" model that favoured independent General Skilled Migrants, to a "hybrid model" that balances supply driven migration against Employer Sponsored "demand driven" migration. van de Ven and Voitchovsky (2014) report estimates for the period between 2005 and 2009, which indicate that this shift to a hybrid model for selection substantively improved labour market outcomes amongst skilled migrants. Here we explore the channels through which improved labour market outcomes were achieved. Our investigation emphasises the likely importance of English language and experience in delivering improved employment outcomes, aspects that are imperfectly controlled for in our first empirical study.
\end{abstract}

We wish to thank David Smith, Bob Birrell, Hielke Buddelmeyer, Deborah Cobb-Clark, Paul Jensen, Guyonne Kalb, and Lesleyanne Hawthorne for useful comments on earlier drafts. van de Ven thanks the Melbourne University Faculty Grant scheme for funding. Voitchovsky thanks the Swiss National Science Foundation for financial support. The usual disclaimers apply.

Key words: Skilled migration, Australia, migrant employment outcomes

JEL Classifications: J15, J61, J24. 


\section{Introduction}

Immigration is increasingly being used by OECD countries to off-set the effects of declining fertility and increased longevity (e.g. http://stats.oecd.org; Keely, 2009). This trend motivates interest in the factors that determine successful migrant labour market integration. There is broad agreement that language skills, levels of education, recognition of qualifications, and social skills all have an important influence on how well immigrants fare in the receiving country's labour market (e.g. Miller and Neo, 2003, Cobb-Clark, 2003, Cobb-Clark et al., 2005). There is also broad agreement that migrants entering under a skills orientated stream differ significantly from, and experience more favourable labour market outcomes to, those entering under other streams (e.g. Antecol et al., 2003, Cobb-Clark, 2000, Miller, 1999). In comparison, the implications of alternative approaches for selecting skilled migrants have received little attention.

Australia has substantively increased its migrant intake during the last decade, with the vast majority of the increase administered through the Skill Stream of Australia's Migration Programme. Between 1996 and 2011, the annual number of permanent migrants to Australia increased from 85000 to 195000. Until 2005, the vast majority of this increase was administered through the General Skilled Migration category, comprised of independent skilled migrants selected via a points-test. Since 2005, however, the Skill Stream of Australia's Migration Programme has been re-balanced in favour of migrants who have sponsoring employers. As a result, Australia's system of skilled migration has been transformed, from a supply-driven model comprised predominantly of independent skilled migrants, to a hybrid model that balances supply-driven migration against demand-driven employer sponsored migration.

The transformation of Australia's system of skilled migration to a hybrid selection model is broadly consistent with international policy trends (e.g. Papademetriou et al., 2008). In the US, for example, where employer sponsored skilled migration predominates, reforms are currently before congress to expand the options available to independent skilled migrants and there is growing interest in the introduction of a points-based skilled migratory scheme (e.g. Koslowski, 2013, p. 28). In Canada, growing evidence that many of its skilled migrants have struggled to find employment commensurate with their skills has shifted emphasis of the public debate from its focus admitting migrants with strong human capital to those who meet the needs of the domestic labour market (e.g. Sweetman and Warman, 2013, Aydemir, 2011). Similarly in Australia, the reforms that have shifted the system of skilled migration to a hybrid model were motivated by a desire to more closely tailor the characteristics of successful skilled migrants to the needs of Australian employers. 
As the preceding paragraph suggests, most contemporary reform of skilled migration policy has been based on prima facie statistical evidence, including trends observed through time within a country, or the relative performance of migrants between countries. In a recent study (van de Ven and Voitchovsky, 2014), we use a difference-in-differences statistical approach to estimate the effects of the shift in Australian skilled migration policy implemented between 2005 and 2009. In that study, we find that the set of policies that underlie the transition from a supply-driven to a hybrid model of skilled migration resulted in significantly higher rates of employment amongst independent skilled migrants, in addition to somewhat weaker statistical evidence of an improvement in the occupational distribution of employed skilled migrants.

In van de Ven and Voitchovsky (2014), special care is taken to ensure that only the variables that are highly comparable between waves of data, are included in the statistical analysis. This analytical approach is necessary to permit meaningful interpretation of results derived from the statistical method that is employed. It also, however, limits our ability to identify the channels through which improvements in migrant employment outcomes were achieved.

Here, we report findings from a further investigation into the potential drivers of the effects of the shift in Australia's skilled migration policy on short-run employment outcomes. This investigation considers on the same data sources as in van de Ven and Voitchovsky (2014), but is based on a more heuristic methodology which permits a richer set of data to be included for analysis. While the analytical approach that we adopt here does not allow very precise statistical conclusions, it does provide a richer picture of the changes that accompanied Australia's reform of skilled migration policy between 2005 and 2009.

We find that imposition of more binding conditions on English language and experience are likely to have been important in driving the positive effects on skilled migrant employment outcomes of policy reforms implemented between 2005 and 2009. Furthermore, our analysis suggests that the importance of these factors was not identified in the empirical study by van de Ven and Voitchovsky (2014), due to the limitations of certain covariates that are considered in that study.

Section 2 gives the policy historical background, including details of the reforms considered for analysis. Our statistical analysis is presented in Section 3, and Section 4 concludes. 


\section{Policy Change in Context}

\section{$1.1 \quad$ Historical background}

There were intense fears in Australia during World War II that seven million people were too few to defend a landmass of 7.5 million square kilometres (cf. 9.8 million $\mathrm{km}^{2}$ in the US, and 10.2 million $\mathrm{km}^{2}$ in continental Europe). This led to the establishment in 1945 of Australia's ministry for immigration, which sought to encourage domestic support for immigrants under the slogan "populate or perish". The primary objective of expanding the Australian population - initially for defence purposes, and later to increase industrial capacity - has continued through to the present day, during which time 8.1 million permanent migrants have arrived in the country. ${ }^{2}$ Data reported for 2011 by the OECD (the most recent series available) indicate that Australia had the third highest proportion of residents born overseas (26.6 per cent), slightly behind Switzerland (27.3 per cent), and more substantively behind Luxembourg (42.1 per cent). In comparison, the share of foreign born nationals was 20.7 per cent in Canada, 13.0 per cent in the United States, and was lowest amongst 28 OECD countries in Poland at 1.8 per cent. $^{3}$

Permanent immigration to Australia is primarily administered under the Migration Programme. There are two major streams to the Migration Programme: the Skill Stream is for people with skills that are likely to contribute to the Australian economy; and the Family Stream permits reunion of immediate family members. ${ }^{4}$ The only other pathway to permanent residence in Australia is through the Humanitarian Programme for refugees. ${ }^{5}$

Since the mid-1980's, Australian immigration policy has placed an increasing emphasis on the suitability of prospective immigrants for the local labour market. Between 1985 and 2012, the share of all visa outcomes that were administered under the Skill Stream of the Migration Programme

\footnotetext{
${ }^{1}$ The slogan "populate or perish" is attributed to former prime minister William Morris (Billy) Hughes (18621952), and was taken up by Arthur Calwell (1896-1973), Australia's first minister for immigration.

${ }^{2}$ Permanent and Settler arrivals between October 1945 and June 2012 reported by the Department of Immigration and Citizenship (DIAC), Historical Migration Statistics, Tables 1.1, 1.2, 1.3, 1.4 and 2.1.

${ }^{3}$ Table A.4. Stocks of foreign-born population in OECD countries and the Russian Federation, International Migration Outlook 2013, OECD.

${ }^{4}$ There is also a Special Eligibility Stream for small groups including former Australian residents and people subject to resolution of status.

${ }^{5}$ We do not address illegal immigration in this study.
} 
more than quadrupled, from 15 to 63 per cent. ${ }^{6}$ This increase was primarily at the expense of the Family Stream - traditionally the most prominent migratory pathway - which declined from 64 per cent of all visa outcomes in 1985 to 29 per cent in 2012. ${ }^{7}$ The substantive increase in the relative size of the Skill Stream between 1985 and 2012 was driven by both the economic cycle and policy reforms.

The proportion of migrants entering Australia via the Skill Stream tends to increase with the economic cycle, as does the total number of the migrant intake. In 1984/85, Australia reached the trough of a deep recession that began in 1982/83. This recession coincided with historically low visa outcomes and migrant arrivals. From this low-ebb, the total number of visa outcomes increased from 69,000 (in the year to June 1985), to 136,000 in the year to June 1989. During the same period, the share of all outcomes administered via the Skill Stream increased from 15 to 38 per cent. Both the number of visa outcomes and the proportion of visas granted via the Skill Stream closely tracked the economic cycle until 1996, following the economy up during the boom of 1989, and down during the recession of 1990/91.

On 3 July 1996 the Australian Minister for Immigration and Multicultural Affairs announced that "Skilled migrants make a particular contribution to Australia's economic development and their representation will be increased". ${ }^{8}$ Following this announcement, the proportion of all visas granted via the Skill Stream jumped from 24 per cent in the year to June 1996 to 41 per cent in 1997. This increase in the share of the Skill Stream was in spite of a fall of 14,000 in the total number of visa outcomes during the same period.

\footnotetext{
${ }^{6}$ The discussion here focusses exclusively on migratory pathways to permanent residency, and therefore excludes Visitor and Temporary Visas (including the Skilled Temporary 457 visa subclass). This selection is motivated by data reported in official publications, and by the data considered for analysis. We also refer to "visa outcomes", which are defined as the number of visas granted in a given year, less visas revoked and temporary visas not granted permanent residency. Note that visa outcomes include both Primary Applicants, upon whose characteristics a visa application predominantly depends, and their dependents. In general, there is a larger proportion of dependents included in the outcomes reported for the Skill Stream than the Family Stream.

${ }^{7}$ Tables 3.2 and 4.1, Historical Migration Statistics, DIAC. Although the share of visa outcomes administered through the Humanitarian Programme also fell substantively between 1985 and 2012, the absolute numbers of visa outcomes of the Humanitarian Programme was relatively stable during the period, fluctuating within a band of between 10,000 and 16,000 per year.

${ }^{8}$ P. Ruddock, cited by Phillips and Spinks (2012):

http://parlinfo.aph.gov.au/parlInfo/search/display/display.w3p;query=Id\%3A\%22media\%2Fpressrel\%2FO3Z20 $\% 22$
} 
The 3 July 1996 announcement marked a sustained and profound re-orientation of Australian immigration policy towards a larger migrant intake, with a strong emphasis on economic migration. From 1996, permanent additions to the Australian population climbed fairly steadily, from 99,000 (in the year to June 1996) to an historical high of 190,000 in $2006 / 7$, a rate of migrant arrival not matched outside of two brief peaks in 1949/50 and 1969/70. ${ }^{9}$ Since then, the number of permanent additions to Australia has continued to grow, and exceeds 245,000 in the most recently available data (2011/12). The vast majority of this increase in Australia's migrant intake was administered through the Skill Stream.

Repeated Governments have stated that the primary objective of the recent expansion of Australia's Migration Programme is to offset the economic pressures of population aging and belowreplacement fertility rates ${ }^{10}$. The shift in favour of the Skill Stream is designed to support this objective, by promoting "migrants with high level vocationally specific skills who can quickly find employment in their occupation" (Birrell et al., 2006, p. 162). The methods used to select skilled migrants have consequently been the subject of intense policy debate, to which we now turn.

\subsection{Management of skilled migration to Australia}

The Skill Stream of the Migration Programme is predominantly comprised of two visa categories, which are distinguished by whether or not an applicant is sponsored by an Australian employer. Employer Sponsored visa applicants require an employer to commit to employ them full time for a minimum period, in a legitimate position that requires a skilled worker. ${ }^{11}$ Skilled individuals who do not benefit from employer sponsorship can apply to migrate independently to Australia through the General Skilled Migration (GSM) category. ${ }^{12}$ GSM visa applicants are assessed on the basis of a

\footnotetext{
${ }^{9}$ Permanent additions to the Australia population is a different concept to the visa outcomes. Permanent additions are comprised of persons who while already in Australia on a temporary basis are granted permanent residence status, and persons who arrive from overseas and are entitled to stay permanently in Australia; reported in Table 2.1, Historical Migration Statistics, DIAC. Data prior to 1996 refer to permanent and settler arrivals.

${ }^{10}$ See, e.g., comment by James Fox, First Assistant Secretary, Migration and Temporary Entry Division, reported in Birrell et al. (2006), p. 10, and the Ministerial "Forward" to annual editions of Australia's Migration Trends (Population Flows prior to 2011/12), reported by the Department of Immigration and Border Protection.

${ }^{11}$ The minimum period was reduced from three years to two years from 1 July 2012 for employers currently sponsoring someone on a 457 visa (representing the majority of employer-nominated migrants).

${ }^{12}$ There are two further visa categories within the Skill Stream. Business Skills visas accounted for 6 per cent of all visas granted through the Skill Stream in 2011/12. These are designed for individuals who have a desire and capacity to contribute to the Australian labour market through their entrepreneurial effort and/or by making a
} 
points test that takes into account a range of characteristics, including the applicant's age, education, skills, occupation, experience, and language ability.

The management of skilled migration to Australia determines the number of migrants entering through constituent visa categories, and is administered via two policy levers. The first of these is the definition of the eligibility rules for individual visa subclasses. A less obvious, but just as important policy lever is the way that applications for visas are processed. This second aspect of the system is deliberately designed to favour some visa subclasses by reducing processing times, and permitting higher numbers of visas granted in any year.

Employer Sponsored visas receive the highest priority for processing. The number of Employer Sponsored visas granted during any year is un-capped, and therefore depends upon the number of eligible applicants and processing times. In contrast, GSM visas are associated with a lower priority for processing. Furthermore, the number of GSM visas granted during any year is managed to meet planning numbers for the entire Skill Stream that are issued by Government as part of the federal budget (ending 30 June). ${ }^{13}$ This approach to processing implies interesting trade-offs between Skill Stream visa categories. Given a fixed planning number for the Skill Stream, relaxing the eligibility criteria for Employer Sponsored visas will generally imply a compensating tightening of visas issued through the GSM category. Alternatively, increasing the planning number for the Skill Stream in context of invariant demand for Employer Sponsored visas implies an expansion of the GSM visas category. As these details are publicly available, they are also likely to affect the demand for alternative skilled visa subclasses amongst prospective applicants.

Australian immigration policy has altered substantively during the last two decades, in terms of both the regulations governing specific visa subclasses and the constraints imposed on the processing of alternative visa categories. A useful approach for cutting through the complexity of the detailed policy reforms is to focus upon historical variation observed for the numbers and types of visa outcomes. Annual visa outcomes reported for the Migration Programme during the period 1995/96 to $2011 / 12$ are displayed in Figure 1.

financial investment. Distinguished Talent visas account for less than 0.5 per cent of visas granted at any time in the available time series, and are designed for people who have an internationally recognised reputation of outstanding achievement in sport, the arts, or a profession.

${ }^{13}$ The practice of issuing planning numbers for immigration as part of the budget process was introduced in $2007 / 08$. 
Figure 1 sheds additional light on the substantial expansion of the Migration Programme since the mid 1990's, and the extent to which this expansion has been managed through the Skill Stream. The figure reveals that the sharpest shift in the mix between the Family Stream and Skill Stream occurred in the three years from 1995/96 to 1997/98, following the official announcement of a change in policy in July 1996. The share of the Skill Stream continued a gradual increase until 2005/06, by which time it accounted for two thirds of all outcomes administered through the Migration Programme.

Figure 1 also indicates that between 1995/96 and 2005/06, the vast majority of the expansion of the Skill Stream was administered through the GSM category. In 1995/96 visa outcomes in the GSM category accounted for just over half of all outcomes administered under the Skill Stream, a fraction that climbed to just under 80 per cent in $2005 / 06$. This disproportionate share of the GSM category is the reason why Australian skilled migration could reasonably be described as "supply-driven" at that time.

An important shift in policy is evident from 2005/06, manifested in two features of the data displayed in Figure 1. First, the Family Stream has grown broadly in line with the Skill Stream during the seven years to $2011 / 12$, so that the relative decline of the Family Stream between 1995/98 and 2005/06 appears to have come to an end. The Family Stream now accounts for approximately one in every three visa outcomes administered through the Migration Programme. Secondly, there is a sharp shift evident within the Skill Stream in favour of Employer Sponsored visas. The proportion of all Skill Stream outcomes administered through the GSM category fell from approximately 80 per cent in 2005/06 to 50 per cent since 2009/10, with most of the shift into Employer Sponsored visas. Contemporary data consequently suggest that Australian skilled migration is now appropriately referred to as a "hybrid" system.

The Global Financial Crisis appears to have been an important catalyst that accelerated the transition in favour of Employer Sponsored migration referred to above. On 17 December 2008, the Minister for Immigration and Citizenship announced Government "concerns that the permanent Skilled Migration program was not delivering the right skills to the right areas and there was an increasing use of the temporary skilled migration program (Subclass 457 visa) by employers to meet their needs", Evans (2008). Reforms were subsequently implemented to fast-track Employer Sponsored permanent migration visas, and GSM visas for applicants with skills identified as in particularly short supply. 
The shift of the Skill Stream in favour of Employer Sponsored migrants has been achieved by altering policy in relation to both GSM and Employer Sponsored visa subclasses. One important and openended feature of reforms to skilled migration policy is the identification of occupations that qualify for skilled migration to Australia. These occupations are defined by official lists ${ }^{14}$, and are under constant review to ensure that they reflect evolving public priorities and labour market needs.

Beyond lists of eligible occupations, however, GSM and Employer Sponsored visas have been subject to appreciably different sets of policy initiatives. In the case of GSM visas, attention has focussed on the specification of the points test used to identify eligible migrants. In March 2006, Birrell et al. (2006) published a review commissioned by the Government "to examine Australia's selection processes for skilled migrants". The review recommended that GSM selection criteria should place greater emphasis on English language proficiency and relevant work experience. These recommendations were accepted by the Government, and associated changes to policy became effective from 1 September 2007, see e.g. Vanstone (2007).

The points test was adjusted to benefit applicants with advanced Australian tertiary qualifications, Australian skilled work experience and strong English language skills. The required English language level was lifted from a score of 5 (vocational) to 6 (competent) on the International English Language Testing System (IELTS) scale for all applicants, except those with recognised trade skills (who required an IELTS score of 5). A substantial fraction of prospective migrants now fail to meet the revised English language requirements (see, e.g. Hawthorne, 2012). Furthermore MODL points were limited to applicants with relevant work experience, and work experience requirements were standardised across all off-shore GSM visa subclasses.

The increased emphasis on language and experience at the expense of education implied that a higher proportion of foreign students studying at Australian education institutions were made ineligible to apply for permanent residency immediately after their graduation. An 18 month temporary working (485) visa was also introduced in 2007 to give these individuals the opportunity to gain the language skills and employment experience they needed to apply for permanent residency. ${ }^{15}$ This shift in favour of a multi-stage migration process is also a common trend

\footnotetext{
${ }^{14}$ Independent GSMs currently require skills in occupations defined by the Skilled Occupation List (SOL). Employer and State Sponsored migrants can have skills in occupations defined by either the SOL or the Consolidated Sponsored Occupation List (CSOL).

${ }^{15}$ Visa subclass 485 has (since March 2013) been turned into a temporary work visa valid for up to 4 years, and is no longer a direct pathway to permanent residency.
} 
throughout the Australian Migration Programme, where the proportion of all visas granted to onshore applicants has increased from 33 to 57 per cent in the ten years to 2012/13. ${ }^{16}$

In contrast, policy initiatives in relation to Employer Sponsored visas have generally focussed on facilitating the matching process between prospective sponsors and interested migrants. As noted by the Minister for Immigration and Citizenship as part of the 2006 Government budget announcement, for example:

"This year we have worked extremely hard to increase the proportion of skilled migrants sponsored by employers or States and regions. We have done this by matching skilled migrants with employers through a number of avenues including skills expos, both onshore and offshore; the availability of Regional Outreach Officers; and for the first time this year Industry Outreach Officers, who we have seconded to key industry groups, to support employers." Vanstone (2006).

The most substantive innovation during recent years has been the introduction of SkillSelect in July 2012, an online pre-screening programme for GSM and Business migrants. Prospective migrants for selected visa subclasses must now submit an expression of interest through SkillSelect before they are invited to submit a formal visa application. This system is designed to give the Australian government greater control over the number and composition of visa applicants, and is a targeted response to the lengthening processing queues that had been observed during the preceding decade.

The set of reforms that have transformed the Australian system of skilled migration from a supplydriven to a hybrid model were primarily motivated by the desire to achieve improved labour market outcomes of skilled migrants. When these reforms were implemented, however, it was unclear what impact they would have. Although van de Ven and Voitchovsky (2014) present empirical estimates which indicate that these reforms had a positive bearing on skilled migrant employment outcomes, that study provides weak evidence of the channels through which these effects were achieved.

In the next section, we report results from an investigation into the likely causes underlying the estimated effects on employment outcomes of changes in skilled migration policy. This investigation uses the same data considered in van de Ven and Voitchovsky (2014), but is based on a heuristic empirical approach that permits a wider set of variables to be taken into consideration.

\footnotetext{
${ }^{16}$ Source DIBP Migration Programme Outcome Data.
} 

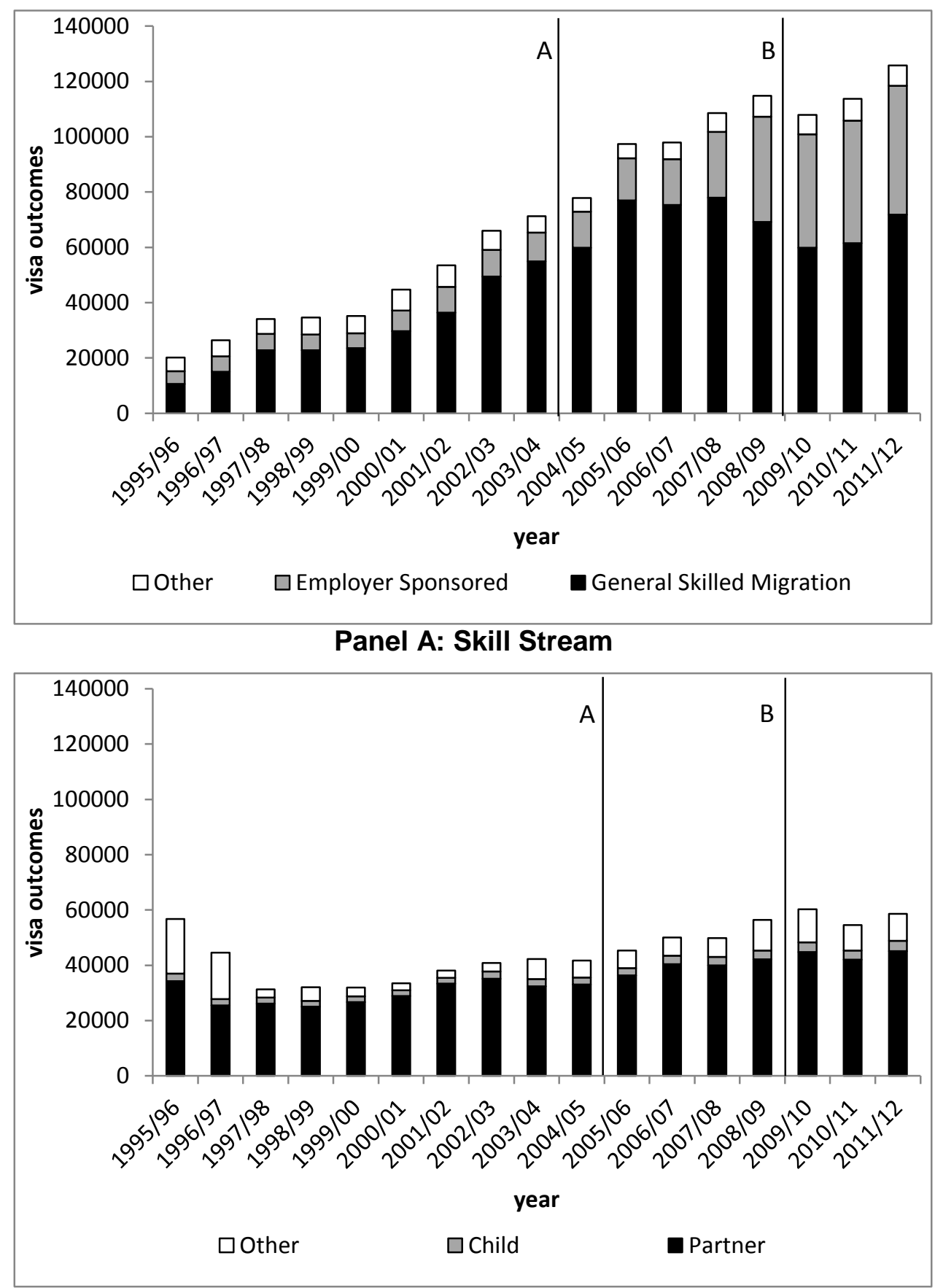

Panel B: Family Stream

Source: Table 2.1 Australia's Migration Trends 2011/12, and Table 2.3 Population Flows: Immigration Aspects 2004, Department of Immigration and Citizenship.

Notes: A: approximate timing of data considered for 2005

B: approximate timing of data considered for 2009, see data appendix for details

"visa outcomes" defined in Section 1.1

Other (Skill Stream) comprised of Business Skills and Distinguished Talents visa subclasses

Other (Family Stream) comprised of Parent and non-dependent child visa subclasses

Figure 1: Migration Programme outcomes by visa category, 1995/96 to 2011/12 


\section{Statistical Analysis}

In van de Ven and Voitchovsky (2014), we report results of a difference-in-differences econometric analysis of the effects of policy reforms implemented between 2005 and 2009 on the employment outcomes of skilled migrants. The data considered were reported by the Longitudinal Survey of Immigrants to Australia 3 (LSIA 3) for 2005 and the Continuous Survey of Australia's Migrants (CSAM) cohorts 1 and 2 for 2009/2010 - see the data appendix for details. Table 1 summarises the treatment effects that we report in that study. The regression specifications numbered 1 to 4 that were considered for each treatment population (General Skilled / Employer Sponsored Migrants) and employment outcome (incidence of employment / incidence of higher occupation given employment) differ by the set of covariates considered for analysis.

Specification 1 includes the smallest possible number of covariates, distinguishing principal applicants by their marriage status, employment of their spouse, dependent children, and time spent in Australia. Specification 2 augments 1 to include controls for self-reported English language proficiency and age as a proxy for experience. This specification is designed to capture the key criteria that were made more important in GSM visa points tests between 2005 and 2009. Specification 3 adds in two education qualification identifiers; one describing education level on a six point scale, and another describing whether the principal applicant obtained their highest qualification in Australia. These variables are interesting because education was made less important in the points test for GSM visas between 2005 and 2009. The fourth and final regression specification includes the full set of covariates considered for the analysis, expanding on specification 3 to allow for differences in reasons for migrating, country of origin, and state of residence.

Table 1 indicates that most of the treatment effects we report in van de Ven and Voitchovsky (2014) are substantial and highly significant. This is particularly true of GSMs taken in isolation, for whom we estimate that policy changes introduced between 2005 and 2009 increased the incidence of employment within the first year of taking up permanent residence by between 10 and 15 percentage points, depending on the specification. This effect is substantial, especially when it is recognised that rates of employment amongst GSMs were in excess of 80 percentage points in 2005. Similarly, we find that the incidence of employment as managers or professionals increased amongst employed GSMs within their first year of taking up permanent residence by between 3 and 10 percentage points between 2005 and 2009.

Reading across the specifications from 1 to 4 within each treatment population and employment outcome provides an indication of the extent to which the estimated treatment effects are 
attributable to alternative explanatory variables. The general impression made by this exercise is that the explanatory variables considered for analysis can explain only a small fraction of the estimated treatment effects.

The largest changes in the estimated treatment effects for the incidence of employment are reported from specification 1 to 2 . The associated regression results indicate that approximately 3 percentage points of the raw treatment effect of between 11 and 15 percentage points can be attributed to changes in English language proficiency and age observed between the 2005 and 2009 samples. The size of this shift is equivalent to approximately 1.5 standard deviations of the estimated treatment effects, and is almost unaffected by the introduction of additional explanatory variables in specifications 3 and 4 . Extending upon this theme, the estimated treatment effects for the incidence of higher occupations amongst the employed are practically unaltered by the alternative sets of covariates considered for analysis.

The set of covariates considered for that study was limited to variables that could be described in an identical fashion between 2005 (LSIA 3) and 2009 (CSAM), with reference to the timing of interviews relative to taking up of permanent residence, the relevant survey questions, the timing of different questions asked and the surveyed population subgroups. The exacting nature of this approach for selecting variables is likely to be one reason why our regression analysis does not provide a clearer picture of the drivers underlying our estimated effects of policy.

One of the limitations imposed on the set of covariates is the difference in timing of the follow-up interviews administered by LSIA 3 and CSAM. The two surveys first contacted Primary Applicants who were granted an on-shore visa or arrived in Australia on an off-shore visa within the six months prior to the respective survey. Both surveys also include a panel dimension, with LSIA 3 re-surveying individuals 12 months following their initial questionnaire, and CSAM re-surveying after a 6 months interval. This difference in timing limited our use of data from the follow-up questionnaires.

As this is one major limitation that we relax in the current study, we begin by discussing the influence that the difference in timing of the follow-up surveys had on associated response rates. We then discuss evidence concerning the likely validity of the explanatory covariates that we consider for language and experience in van de Ven and Voitchovsky (2014), before drawing on a wider set of related variables to improve our understanding of the effects of policy on short-run employment outcomes of skilled migrants between 2005 and 2009. 


\subsection{Timing of follow-up questionnaires and survey non-response}

LSIA 3 and CSAM achieved similar completed response rates for their initial questionnaires, equal respectively to 49 and 47 per cent. LSIA 3 achieved a retention rate for the follow-up questionnaires of $52 \%$. As noted above, the gap between the initial and follow-up questionnaires was halved from LSIA 3 to CSAM, and the retention rate achieved for CSAM improved to $89 \%$. The substantive difference between the average retention rates achieved by LSIA 3 and CSAM was the prime motivation for minimising use of data from the follow-up questionnaires of the two surveys for the difference-in-differences analysis reported in van de Ven and Voitchovsky (2014).

Distinguishing retention rates by visa category reveals that the largest boost in CSAM was observed amongst principal applicants of Family Stream visas, which jumped from $35 \%$ in LSIA 3 to $86 \%$. In contrast, retention rates amongst Skill Stream migrants were relatively high in LSIA 3, at 76\%, and increased relatively modestly to $90 \%$ in cohorts 1 and 2 of CSAM. Our subsequent analysis takes advantage of the fact that retention rates of LSIA 3 and CSAM do not appear to be very substantively different for Skill Stream migrants, suggesting that some insights may be derived by drawing on data for this group.

The difference between the retention rates of Family Stream and Skill Stream migrants is partly due to the influence of language proficiency on survey response. In LSIA 3, for example, the retention rate in the follow-up questionnaire is twice as high amongst individuals who report English to be their main language as those who report speaking English "not well" (59\% c.f. 30\%). The proportion of the LSIA 3 population reporting English to be their main language reaches $45 \%$ for Family Stream migrants, but increases to 63\% for GSMs, and 84\% for Employer Sponsored migrants.

\subsection{Proxies for language and experience}

\section{Language}

Both LSIA 3 and CSAM asked primary applicants in their initial questionnaire to rate their English language proficiency on a four point scale from "not at all" to "very well". Both surveys also asked primary applicants in their follow-up questionnaires to indicate their International English Language Testing System (IELTS) scores, which can range from 0 (low) to 10 (high). The IELTS score is a useful counterpart to self-reported English language proficiency because it is based on an objectively defined measurement criterion. Nevertheless, these data were omitted as covariates from van de Ven and Voitchovsky (2014) because they were reported only in follow-up questionnaires. 
The relationship between IELTS scores and self-reported English language proficiency for Skill Stream migrants (who were not born in an English-speaking country) is described by Table 2. The selfreported scores are organised in three groups, "not well/ not at all", "well" and "very well/main language". The top panel of Table 2 reports data from LSIA 3 and the bottom panel reports data from CSAM. Both panels of the table indicate a similar positive gradient between IELTS scores and English language proficiency. Hence, the largest proportion of individuals reporting not speaking English well, also report IELTS scores toward the bottom of the range in both LSIA 3 and CSAM, and vice versa for those reporting English as their main language (ignoring non-response). This observation provides some corroboration of the information content of the two variables as measures of language skill, and supports use of the self-reported English language proficiency as a covariate in van de Ven and Voitchovsky (2014).

Nevertheless, Table 2 does indicate some important differences between LSIA 3 and CSAM that can only be discerned by taking into consideration the reported IELTS scores. One of the most important of these is the substantial rise in the proportion reporting an IELTS score, which increased from $48 \%$ in LSIA 3 to $80 \%$ in CSAM. Furthermore, within the subset of individuals reporting an IELTS score, the proportions reporting higher scores (7 and above) are appreciably higher in CSAM than in LSIA 3. This second observation is in contrast to the relatively minor fluctuations between LSIA 3 and CSAM in the proportions of the population with alternative self-reported English language ability within this group.

It is impossible to say for certain why these shifts in reported IELTS scores occurred. The higher rates of response may, for example, be a simple artefact of the shorter delay between the initial and follow-up questionnaires administered by CSAM. Nevertheless, the shifts reported for IELTS scores are generally consistent with associated policy changes implemented between 2005 and 2009, which increased both the range of visa subclasses requiring applicants to submit an IELTS score, and the minimum score thresholds required for visa eligibility. Furthermore, there is some evidence discussed in section 3.3 below - that English language declined as an impediment to finding work amongst GSMs in 2009, relative to 2005. As a result, the statistical analysis reported in van de Ven and Voitchovsky (2014) may fail to capture the full contribution made by language toward achieving the improvement in short-run employment outcomes estimated for skilled migrants between 2005 and 2009. 


\section{Experience}

Labour market experience is interesting for our analysis because experience was made more important in the selection criteria for GSM visas by the policy reforms implemented between 2005 and 2009. Age is used as a proxy for experience in van de Ven and Voitchovsky (2014), as this was the only available variable that satisfied the variables selection criteria imposed in that study. LSIA 3 and CSAM do, however report some data for labour market experience of principal applicants prior to their arrival in Australia. We discuss this supplementary detail here.

The initial questionnaire of LSIA 3 asked all respondents whether they had "ever done any paid work" before coming to Australia. ${ }^{17}$ A related question was included in CSAM, in the follow-up questionnaire of cohort 2 only, and asked employed principal applicants they were "now working at the same, higher or lower level of responsibility, relative to your previous job in your home country". One possible answer was that the respondent had never worked prior to arriving in Australia. Table 3 reports statistics calculated on these data that are designed to facilitate comparisons between the series reported by LSIA 3 and CSAM.

Table 3 indicates a number of interesting features concerning the incidence of foreign labour market experience amongst principal applicants of skill stream visas (only) who were reported as employed in the follow-up surveys administered by LSIA 3 and cohort 2 of CSAM. First, the proportion of this entire population subgroup reporting some foreign labour market experienced increased by just under 20 percentage points. In part, this is attributable to the fact that respondents tended to be older in CSAM than in LSIA 3, and older respondents tend to have higher rates of foreign experience. It is, however, also due to increased foreign experience reported within age groups. The incidence of foreign experience amongst migrants under age 25 increased by 23 percentage points, almost doubling from LSIA 3 to CSAM. The same ratio also increased for individuals aged 25 to 34 , from 78 to 89 per cent. These substantive increases in age specific rates of foreign experience underscore the imperfect nature of age as a proxy for experience in this context.

Almost all employer sponsored migrants report having some foreign labour market experience in both LSIA 3 and CSAM. Hence, the increase in rates of foreign experience that is cited above was due both an increase in foreign experience amongst GSMs and the shift in the Skill Stream in favour of

\footnotetext{
${ }^{17}$ The exact question was: "Before coming to Australia did you ever do any paid work in your former home country?"
} 
Employer Sponsored migration. Both of these shifts are consistent with changes to migration policy implemented between 2005 and 2009.

These observations, taken together, suggest that the policy reforms resulted in greater (foreign) labour market experience amongst skilled migrants, and that this increase is imperfectly captured by controls for migrant age. Furthermore as the pronounced rise in rates of labour market experience coincided with improved employment outcomes amongst skilled migrants, we are inclined to conclude that there exists an important causal relationship that is not fully represented in the statistical analysis reported in van de Ven and Voitchovsky (2014). Further indirect evidence supporting this conclusion is presented below.

\subsection{Job search, sorting, and satisfaction}

\section{$\underline{\text { Search }}$}

The follow-up surveys issued for both LSIA 3 and CSAM asked survey respondents that had been out of employment for some period since the initial questionnaire ${ }^{18}$, whether they had experienced difficulties in finding work, and if so about the underlying causes for those difficulties. Responses to these questions indicate that, the proportion of principal applicants reporting some difficulty in finding work increased amongst those with Family Stream visas, from 18 to 26 percentage points between 2005 and 2009, while the proportion of applicants experiencing difficulties remained stable amongst independent GSMs (13 and 12 percentage points, in 2005 and 2009 respectively). ${ }^{19}$ This shift is consistent with the improvement of employment rates observed amongst GSMs, relative to Family Stream migrants, in the context of a harsher economic environment in 2009.

Interestingly, amongst those who experienced some difficulty in finding work, migrants with both Family Stream and GSM visas cite a similar set of underlying causes in their responses to LSIA 3. English language difficulties, not enough jobs, insufficient work experience, and insufficient local labour market experience in particular are the most commonly cited reasons why migrants struggled to find work in 2005.

Comparing data reported by cohorts 1 and 2 of CSAM against data reported by LSIA 3 reveals very little change in the main reasons cited by migrants who struggled to find work. The most notable

\footnotetext{
${ }^{18}$ The question related to the last 12 months in LISA3 and to the last 6 months in CSAM.

${ }^{19}$ Unsurprisingly, very small numbers of Employer Sponsored migrants report any difficulty in 2005 and 2009.
} 
exception in this regard is that migrants with GSM visas tend to be far less likely to cite their English language ability as a factor limiting their ability to find work in CSAM. This suggests that reforms to increase English language requirements for GSM visas were broadly successful. In contrast, insufficient experience continues to be cited as a principal limiting factor by GSMs, suggesting that reforms to make experience more prominent in skilled migrant selection criteria could be extended further.

\section{$\underline{\text { Sorting }}$}

Questions asked about the relationship between the current field of work of those working, and their preferred or nominated field of work tend to vary fairly substantively between LSIA 3 and CSAM and should be compared with caution, but some broad trends of interest are evident. In general, it appears that many skilled migrants to Australia do find work in a related field to that nominated in their visa application. Data reported in the follow-up survey of LSIA 3, for example indicate that 41 per cent of GSMs, and 52 per cent of Employer sponsored migrants were working in an occupation within a 2 digit ASCO code with their nominated occupation. Related responses to the follow-up questionnaire for CSAM indicate that 81 per cent of GSMs and 87 per cent of Employer Sponsored migrants said that they were working in a closely related field to their nominated occupation.

The follow-up questionnaire reported by CSAM includes information about the reasons why individuals were not working in their nominated occupations. Although small samples for Employer Sponsored migrants make the associated data unreliable, the principal reasons given by GSMs for not working in their nominated occupations included lack of jobs or opportunity (45\%), insufficient work experience (26\%), and lack of Australian license or registration (14\%). These results echo those discussed in relation to the cited difficulties associated with finding work, and underscore the continuing importance of experience despite the greater focus that this factor received as part of the skilled migrant reforms implemented between 2005 and 2009.

\section{Satisfaction}

Employed principal applicants are asked questions about their job satisfaction in both the initial questionnaire and follow-up interview administered for LSIA 3, and in the follow-up interview administered for CSAM. These data indicate generally high rates of satisfaction throughout, with slightly higher rates of satisfaction reported in CSAM than LSIA 3. 
Employer Sponsored migrants tend to report the highest rates of satisfaction in both surveys. The proportion indicating that they "like the job" was 79 per cent for the initial questionnaire of LSIA 3, 83 per cent for the follow-up questionnaire of LSIA 3, and 83 per cent for CSAM, rising to 97, 96, and 99 per cent respectively when including responses to "the job is okay". Slightly lower rates of job satisfaction are reported by GSMs, with 84 per cent indicating that their job is at least "okay" in the initial questionnaire of LSIA 3, rising to 93 per cent in the follow-up questionnaire, and the 96 per cent in CSAM. The figures for Family Stream migrants at work are generally similar, rising from 87 per cent reporting that their job is at least okay in the initial questionnaire of LSIA 3, to 90 percent in the follow-up questionnaire, and then 95 per cent in CSAM.

Hence, very similar differences between measures of job satisfaction are reported over the three sets of survey questions for Family Stream, GSM and Employer Sponsored migrants. This suggests that the policy changes implemented between 2005 and 2009 did not substantively alter the "quality" of jobs taken up GSM and Employer Sponsored migrants, relative to Family Stream migrants. Nevertheless, the reweighting in favour of Employer Sponsored migrants within the Skill Stream, combined with the very high rates of satisfaction reported by Employer Sponsored migrants, does point toward a general improvement amongst skilled migrants on average, even if the associated differences are not particularly substantial. These general findings all echo the estimated treatment effects reported for the incidence of employment in higher occupations, as discussed at the beginning of this section.

\section{Conclusions}

In the early 2000's Australia's system of skilled migration predominantly awarded permanent visas to independent skilled migrants selected via a points test. This disproportionate reliance on supplydriven migration declined with reforms implemented between 2005 and 2009, which increased the requirements for supply-driven points-based independent migrants at the same time as demanddriven employer-sponsored migration was being actively promoted by government. Van de Ven and Voitchovsky (2014) estimate that this combination of policy adjustments substantially improved employment outcomes for skilled migrants in their first year of taking up permanent residency. This study reports results of our investigation into the likely channels through which these improvements in employment outcomes were achieved.

We present evidence that controls for language and experience introduced as explanatory variables for the effects on employment outcomes in van de Ven and Voitchovsky (2014) are likely to understate the associated effects of policy on respondent characteristics. 
In relation to the former, the coarse nature of the variable for self-reported English language skills (a 4 point scale) that is included in van de Ven and Voitchovsky (2014) obscures improvements in English language ability that are described by IELTS scores. This is particularly the case for individuals who report that English is their main language - the highest self-reported category, and almost the most prevalent. Here, the IELTS scores provide additional detail, indicating appreciable improvements in English language skills from 2005 to 2009 consistent with associated policy reforms.

It is well recognised that, for many occupations - and high skilled occupations in particular - very strong language skills are important in determining labour market success. This suggests that policy reforms promoting improved language skills are likely to have been crucially important in achieving the estimated improvements in skilled migrant employment outcomes. This conclusion is also supported by the virtual disappearance between 2005 and 2009 of survey respondents that identify English language as a key factor limiting their labour market success.

We also report evidence indicating that age, as considered by van de Ven and Voitchovsky (2014), is a very approximate control for experience in the context considered here. Data reported in this study do support a positive relationship between age and experience. As the average age of skilled migrants did increase between 2005 and 2009, some experience effect is controlled for in the study by van de Ven and Voitchovsky (2014). But the analysis we report here indicates that experience within age bands is also likely to have increased non-trivially between 2005 and 2009, so that the associated effect of experience on employment outcomes is likely to be understated in the empirical analysis of van de Ven and Voitchovsky (2014). The importance of this form of measurement error on the analysis is underscored by data identifying experience as one of the chief impediments to labour market success cited by migrants in both data for both 2005 and 2009.

Responses to ancillary questions for job search, sorting, and satisfaction all tend to reinforce the general conclusions arrived at through other aspects of our empirical study of the 2005 to 2009 reforms to Australian skilled migration policy: that skilled migrants in 2009 were better able to find work, and that the quality of the work that they found in 2009 may have improved slightly, relative to 2005. These results therefore provide support for the shift toward a system for selecting skilled migrants, which imposes stringent eligibility conditions on independent applicants, and requires less well-equipped migrants to seek employer sponsorship as a precondition for migration. 


\section{References}

Antecol, H., Cobb-Clark, D.A. \& Trejo, S.J. (2003), "Immigration policy and the skills of immigrants to Australia, Canada, and the United States", Journal of Human Resources, 38, pp. 192-218.

Aydemir, A. (2011), "Immigrant selection and short-term labor market outcomes by visa category", Journal of Population Economics, 24, pp. 451-475.

Birrell, B., Hawthorne, L. \& Richardson, S. (2006), Evaluation of the General Skilled Migration categories. Canberra: Department of Immigration and Border Protection.

Cobb-Clark, D.A. (2000), “Do selection criteria make a difference? Visa category and the labour market status of immigrants to Australia", Economic Record, 76, pp. 15-31.

Cobb-Clark, D.A. (2003), "Public policy and the labor market adjustment of new immigrants to Australia", Journal of Population Economics, 16, pp. 655-81.

Cobb-Clark, D.A., Connolly, M.D. \& Worswick, C. (2005), “Post-migration investments in education and job search: A family perspective', Journal of Population Economics, 18, pp. 663-90.

Evans, C. (2008). Migration program gives priority to those with skills most needed, media release 17 December 2008, viewed 15 January 2014, http://www.minister.immi.gov.au/media/mediareleases/2008/ce08123.htm

Hawthorne, L. (2012), "International medical migration: what is the future for Australia?", MJA Open, 1, pp. 18-21.

Keeley, B. (2009), International Migration: The Human Side of Globalisation. Paris: OECD.

Koslowski, R. (2013), "Selective migration policy models and changing realities of implementation", International Migration, 52, pp. 26-39.

Miller, P.W. (1999), "Immigration policy and immigrant quality: the Australian points system", American Economic Review, 89, pp. 192-197.

Miller, P.W. \& Neo, L.M. (2003), “Labour market flexibility and immigrant adjustment”, Economic Record, 79, pp. 336-56.

OECD. (2013). International Migration Outlook 2013. OECD Publishing.

Papademetriou, D. G., Somerville, W. \& Tanaka, H. (2008). Hybrid Immigrant-Selection Systems: The next generation of economic migration schemes. Washington, DC: Migration Policy Institute.

Phillips, J. \& Spinks, H. (2012), "Skilled migration: temporary and permanent flows to Australia", Background Note, December, Department of Parliamentary Services.

Puhani, P. A. (2012), "The treatment effect, the cross difference, and the interaction term in nonlinear "difference-in-differences" models", Economics Letters, 115, pp. 85-87. 
Ruddock, P. (1996). Migration programme revamped to benefit Australia, media release, 3 July 1996, viewed 13 May 2014

Smith, D., Kovac, E. \& Woods, M. (2012), The Continuous Survey of Australia's Migrants: Cohorts 1 to 5 report 2009-11. Department of Immigration and Citizenship: Canberra.

Sweetman, A. \& Warman, C. (2013), “Canada's immigration selection system and labour market outcomes", Canadian Public Policy, 39, pp. S141-S164.

van de Ven, J. and S. Voitchovsky (2014). "Skilled migrants and labour market integration: how important is the selection process?", mimeo.

Vanstone, A, (2006), Government successfully matching skilled workers to employers, Media release, 1 May. Viewed 21/07/2014 through the Australian Parliamentary website.

Vanstone, A. (2007). Minister for Immigration and Citizenship, to Population Flows: Immigration Aspects 2007. 
Table 1: Estimated treatment effects for Primary Applicants of Family Stream and Skill Stream visas aged 18-54 by sex, visa class, regression specification and dependent variable

\begin{tabular}{|c|c|c|c|c|c|c|c|c|}
\hline \multirow{2}{*}{$\begin{array}{l}\text { treatment population } \\
\text { regression specification }\end{array}$} & \multicolumn{4}{|c|}{ GSMs only } & \multicolumn{4}{|c|}{ GSM and Employer Sponsored migrants } \\
\hline & 1 & 2 & 3 & 4 & 1 & 2 & 3 & 4 \\
\hline \multicolumn{9}{|c|}{ Incidence of employment } \\
\hline \multirow[t]{2}{*}{ treatment effects** } & 0.1437 & 0.1158 & 0.1144 & 0.1081 & 0.1205 & 0.0936 & 0.0895 & 0.0853 \\
\hline & $(0.0248)$ & $(0.0257)$ & $(0.0263)$ & $(0.0275)$ & $(0.0205)$ & $(0.0205)$ & $(0.0208)$ & $(0.0218)$ \\
\hline \multirow[t]{2}{*}{ for men } & 0.1526 & 0.1289 & 0.1229 & 0.1094 & 0.1162 & 0.0938 & 0.0867 & 0.0788 \\
\hline & $(0.0263)$ & $(0.0273)$ & $(0.0279)$ & $(0.0288)$ & $(0.0212)$ & $(0.0210)$ & $(0.0212)$ & $(0.0218)$ \\
\hline \multirow[t]{2}{*}{ for women } & 0.1287 & 0.0941 & 0.1003 & 0.1060 & 0.1288 & 0.0934 & 0.0949 & 0.0979 \\
\hline & $(0.0224)$ & $(0.0229)$ & $(0.0235)$ & $(0.0253)$ & $(0.0192)$ & $(0.0195)$ & $(0.0200)$ & $(0.0217)$ \\
\hline \multicolumn{9}{|c|}{ Incidence of higher occupation given employment } \\
\hline \multirow[t]{2}{*}{ treatment effects** } & 0.0655 & 0.0662 & 0.0800 & 0.0984 & 0.0528 & 0.0469 & 0.0583 & 0.0692 \\
\hline & $(0.0376)$ & $(0.0384)$ & $(0.0364)$ & $(0.0361)$ & $(0.0347)$ & $(0.0353)$ & $(0.0326)$ & $(0.0323)$ \\
\hline \multirow[t]{2}{*}{ for men } & 0.0383 & 0.0511 & 0.0704 & 0.0960 & 0.0361 & 0.0376 & 0.0527 & 0.0679 \\
\hline & $(0.0375)$ & (0.0389) & $(0.0360)$ & $(0.0354)$ & $(0.0350)$ & (0.0359) & $(0.0321)$ & $(0.0316)$ \\
\hline \multirow[t]{2}{*}{ for women } & 0.1126 & 0.0924 & 0.0967 & 0.1026 & 0.0857 & 0.0655 & 0.0694 & 0.0717 \\
\hline & $(0.0377)$ & $(0.0376)$ & $(0.0372)$ & $(0.0374)$ & $(0.0343)$ & $(0.0340)$ & $(0.0335)$ & $(0.0336)$ \\
\hline
\end{tabular}

Source: regressions calculated using STATA on pooled data reported for visa principal applicants in the initial waves of LSIA 3 and cohorts 1 and 2 of CSAM

Notes: control population refers to Family Stream migrants and treatment period reported by CSAM data

standard errors in parentheses

pooled sample size is 11973 for Family Stream and GSM migrants, and 14367 for Family Stream, GSM and Employer Sponsored migrants

proportion of pooled sample employed is 67.5 per cent for GSMs only, and 72.4 for GSM and Employer Sponsored migrants

* predicted employment evaluated using threshold probability of $50 \%$

** treatment effect = population average impact of treatment on probability of employment/higher occupation for treated population in treatment period (see Puhani, 2012)

treatment effect calculated by evaluating predicted probabilities of employment implied by the estimated model

higher occupation defined as "managers" and "professionals"

all models interact all covariates with the gender dummy variable

specification 1 includes covariates for marriage, employed spouse, dependent children, onshore visa, and time in Australia

specification 2 augments specification 1 to include English language and age covariates

specification 3 augments specification 2 to include education qualifications covariates

specification 4 augments specification 3 to include a wide range of covariates including reasons for migrating, country of origin and state of residence 
Table 2: Relationship between self-reported English language proficiency and International English Language Test System (IELTS) scores - percentages of population

\begin{tabular}{l|ccccc}
\hline & \multicolumn{5}{c}{ self-reported spoken English language skills } \\
IELTS scores & missing & not well & well & very well & total \\
\hline \multicolumn{5}{c}{2005 (LSIA 3) - 2287 observations } \\
\hline not known & 0.8 & 1.5 & 15.1 & 34.5 & 51.9 \\
3 to 5.5 & 0.2 & 1.1 & 4.2 & 2.1 & 7.6 \\
6 to 6.5 & 0.1 & 0.5 & 11.3 & 9.1 & 21.0 \\
7 to 7.5 & 0.2 & 0.0 & 3.8 & 10.9 & 15.0 \\
8 to 10 & 0.1 & 0.0 & 0.4 & 4.0 & 4.5 \\
Total & 1.4 & 3.1 & 34.8 & 60.7 & 100.0 \\
\hline \multicolumn{5}{|c}{$2009 / 10$ (CSAM cohorts 1 and 2$)-2387$ observations } \\
\hline not known & 0.1 & 2.6 & 4.1 & 13.2 & 20.0 \\
3 to 5.5 & 0.0 & 1.4 & 5.8 & 1.9 & 9.1 \\
6 to 6.5 & 0.4 & 0.4 & 10.4 & 12.1 & 23.3 \\
7 to 7.5 & 0.3 & 0.1 & 8.7 & 22.5 & 31.7 \\
8 to 10 & 0.0 & 0.0 & 1.2 & 14.6 & 15.9 \\
Total & 0.7 & 2.0 & 26.1 & 51.2 & 100.0 \\
\hline \hline
\end{tabular}

Notes: "not well" category includes "not at all"

"very well" category includes "main language"

Table 3: Indirect evidence on incidence of work experience in home country by age Principal Applicants of Skill Stream visas employed in the follow-up questionnaires, reported by LSIA 3 and cohort 2 of CSAM

\begin{tabular}{lrrrrr}
\hline & \multicolumn{6}{c}{ age band } \\
& up to 24 & $25-34$ & $35-44$ & $45-54$ & Total \\
\hline \multicolumn{2}{c}{2005 (LSIA 3) } & & & \\
\hline $\begin{array}{l}\text { sample } \\
\text { \% with foreign work } \\
\text { experience }\end{array}$ & 452 & 1,363 & 671 & 190 & 2,676 \\
\hline & 26.1 & 77.9 & 97.9 & 99.0 & 75.7 \\
\hline sample & 2010 (CSAM cohort 2) & & & \\
\% with foreign work & 58 & 777 & 632 & 203 & 1,670 \\
experience & & & & & \\
higher responsibility & 50.0 & 89.5 & 99.5 & 99.5 & 93.1 \\
same responsibility & 37.9 & 39.3 & 31.3 & 32.5 & 35.4 \\
lower responsibility & 8.6 & 27.2 & 37.5 & 35.5 & 31.4 \\
not known & 3.5 & 22.1 & 29.3 & 30.1 & 25.2 \\
\hline total & 0.0 & 0.9 & 1.4 & 1.5 & 1.1 \\
\hline \hline
\end{tabular}

Note: all statistics except sample sizes report age specific percentages 


\section{Data Appendix}

Our study is based on two complementary data sources for Australian migrants: the Longitudinal Survey of Immigrants to Australia 3 (LSIA 3), and the Continuous Survey of Australia's Migrants (CSAM). LSIA 3 describes the circumstances of migrants in 2005, and CSAM reports data from 2009/10, with the gap between the two surveys corresponding the period during which Australian skilled migration policy shifted towards a "hybrid" model as discussed in Section 1.2.

\section{Sample selection and survey methodology}

LSIA 3 and CSAM were both conducted by the Department of Immigration and Citizenship ${ }^{20}$ and are almost identical, which ensures a high degree of comparability between the two. Both LSIA 3 and CSAM adopt visa Primary Applicants as the basic unit of analysis. Primary Applicants are the individuals upon whose characteristics a visa application is chiefly assessed. The sample frames for both LSIA 3 and CSAM were drawn from the Settlement Database maintained by the Department of Immigration and Citizenship. ${ }^{21}$ The sample populations for both surveys were limited to Primary Applicants for permanent or provisional visas managed under the Migration Programme, who were at least 18 years of age, had an identifiable country of birth, were not New Zealand citizens, and did not have a "special eligibility" visa. ${ }^{22}$ Although both surveys only administered questionnaires to Primary Applicants, there are a small number of questions in each survey where Primary Applicants were asked to provide responses on behalf of other members of the household.

The two surveys contacted Primary Applicants who were granted an on-shore visa or arrived in Australia on an off-shore visa within the preceding six months. The sample for LSIA 3 was first surveyed between August and October 2005 and comprises Primary Applicants who were granted an on-shore visa or arrived in Australia on an off-shore visa between December 2004 and March 2005. Data for CSAM were collected for 5 independent cohorts of immigrants, separated by 6 month intervals, between September 2009 and September 2011. We consider data only for the first two of

\footnotetext{
${ }^{20}$ We refer to the department responsible for managing immigration to Australia throughout this paper as the "Department of Immigration and Citizenship", or more succinctly "the Department". However, immigration to Australia was managed by the "Department of Immigration and Multicultural and Indigenous Affairs" from 26/11/2001 to 26/01/2006, the "Department of Immigration and Multicultural Affairs" from 27/01/2006 to 29/01/2007, the "Department of Immigration and Citizenship" from 30/01/2007 to 17/09/2013, and the "Department of Immigration and Border Protection" from 18/09/2013 to the time of writing.

${ }^{21}$ The Settlement Database has been maintained by the Department of Social Services since early 2014.

${ }^{22}$ Special eligibility visas are issued to people who meet specific criteria, or to resolve the status of certain groups of persons who have been allowed to remain in Australia as long-term temporary residents on humanitarian grounds.
} 
these cohorts, as the initial questionnaire was altered slightly for cohorts 3,4 and 5, complicating comparisons with LSIA 3. ${ }^{23}$ Cohort 1 of CSAM was first surveyed in September 2009 and reports data for Primary Applicants who arrived in Australia or were granted an on-shore visa between January and May 2009. Cohort 2 was first surveyed in March 2010 and reports data for Primary Applicants who were granted an on-shore visa or arrived in Australia on an off-shore visa between July and November 2009; see Smith et al. (2012). The approximate timings of the sample windows for the respective surveys are indicated by vertical lines displayed in Figure 1.

Both LSIA 3 and CSAM include a panel dimension, with an initial survey administered as a written questionnaire that respondents completed and mailed back, and a follow-up survey conducted by telephone interview. Individuals with limited English language ability could obtain access to interpreter services by contacting a toll free number for the initial written surveys, and the follow-up telephone interviews were conducted in a language that was selected using information gained through the initial survey. The follow-up survey was administered 12 months after the initial questionnaire in LSIA 3, and six months after the initial questionnaire in CSAM.

Our analysis considers data for individuals aged 18 to 54 . Applicants for Skill Stream visas must be under age 50 unless exempt. Our age restriction omits 0.9 per cent of Employer Sponsored and GSM migrants in the pooled LSIA 3 / CSAM data. ${ }^{24}$ Additionally, our empirical analysis focusses only on migrants within the Family, independent GSM, and Employer Sponsored visas subclasses. LSIA 3 achieved a completed response rate of 49 per cent and reports data for 9865 respondents to the initial survey. The initial questionnaires for CSAM achieved a similar response rate of 47 per cent. Cohorts 1 and 2 of CSAM together report data for 7217 respondents.

\section{Acknowledgements}

We wish to thank David Smith, Bob Birrell, Hielke Buddelmeyer, Deborah Cobb-Clark, Paul Jensen, Guyonne Kalb, and Lesleyanne Hawthorne for useful comments on earlier drafts. van de Ven thanks the Melbourne University Faculty Grant scheme for funding. Voitchovsky thanks the Swiss National Science Foundation for financial support. The usual disclaimers apply.

\footnotetext{
${ }^{23}$ Additionally the sample size of Family Stream respondents is approximately 1100 in both cohorts 1 and 2 , and drops substantially to approximately 700 in cohorts 3, 4 and 5.

${ }^{24}$ For the entire sample of LSIA and most of CSAM, the threshold age for Skilled Migration was 45 . This age threshold was lifted to 50 in July 2011.
} 